\title{
Primary cutaneous nocardiosis: a diagnosis of consideration in a renal transplant recipient
}

\author{
Priyatam Khadka ${ }^{1,2^{*}}$ and Dibya Singh Shah ${ }^{3}$
}

\begin{abstract}
Background: The cutaneous nocardiosis remains a diagnostic challenge: similar clinical presentations as of cutaneous diseases with different etiology — and the inherent difficulty in cultivating the pathogen.

Case presentation: Herein, we describe a case of primary cutaneous nocardiosis in a renal transplant recipient; treated with anti-tubercular drugs due to misdiagnosis of cutaneous tuberculosis. On clinical examinations, a few red erythematous papules with erosions and crusting seen, over prior surgery scar of renal transplant. Multiple basophilic colonies surrounded by neutrophilic abscesses and granulation tissue were seen on histopathological examinations. The presumptive identification was done by Ziehl-neelson staining, bacterial culture, biochemical interpretations, and susceptibility pattern of the isolates to antibiotics. Radiographic imaging of brain and lungs were normal; no feature of disseminated nocardiosis seen. After 3 months of an anti-microbial therapy i.e. TMP-SMX(sulfamethoxazole and trimethoprim); the patient underwent progressive changes no relapse noted; transplant function observed in a good state, found asymptomatic with limited side effects on a regular follow up till now.
\end{abstract}

Conclusion: Cutaneous nocardiosis can occur in the renal-transplant patient. Therefore, a high degree of clinical suspicions, extensive clinical differentiation, early detection of the pathogen, apt selection of the antimicrobial therapy, correct dosing, and treatment duration is crucial for successful outcomes.

Keywords: Cutaneous nocardiosis, Cutaneous tuberculosis, Immunocompromised, Nocardia asteroides, Renal transplant, Sulfamethoxazole and trimethoprim

\section{Background}

Nocardiosis, the opportunistic infection, most commonly present as pulmonary diseases; however, infrequently may present either as cutaneous or disseminated infections [1]. The rare entity, cutaneous nocardiosis, presents either as a part of disseminated infection or as a primary infection resulting from inoculation [2]. The disease is more frequent in tropical countries, without age or ethnic predilection; although, much common in patients with underlying immunosuppressive therapy for renal transplantation [3]. Moreover, the frequency to acquired nocardiosis

\footnotetext{
* Correspondence: khadka.priyatam@gmail.com

'Department of Microbiology, Tribhuvan University Teaching Hospital, Kathmandu, Nepal

${ }^{2}$ Medical Microbiology, Tri-Chandra Multiple Campus, Tribhuvan University, Ghantaghar, Kathmandu, Nepal

Full list of author information is available at the end of the article
}

varies according to the type of solid organ transplant-highest $3.5 \%$ in lungs transplant recipient, while lowest $(0.004$ to $0.7 \%)$ in renal transplant; lower the incidence higher the chance of being neglected from diagnosis considerations [4-6].

The cutaneous nocardiosis, in contrast to pulmonary or disseminated forms, in the renal transplant recipient, often leading delay in diagnosis and treatment because of relative paucity of the pathogen (Nocardia species), elusive clinical manifestations, difficult microbial entity to grow in-vitro-and appearance on imaging may mimic other entities such as malignancies [3, 7].

We report, herein, a case of primary cutaneous nocardiosis in renal allograft recipient masquerading as cutaneous tuberculosis; was treated successfully with trimethoprim/sulfamethoxazole. 


\section{Case presentation}

A 62-year-old Nepali, a professional health worker, presented in Grande International Hospital with red erythematous papules near around the previous site of renal transplantation(Fig. 1a). He had lived with diabetes and hypertension for 27 years and had a history of visiting the south-western and south-eastern region of the USA. The renal transplantation was done 6 months ago (6th October 2017). The previous diagnosis was made as cutaneous tuberculosis; in a local hospital, based on clinical presentations and unresolved lesion with a course of antimicrobial therapy (cloxacillin). Simultaneously, the patient had received a course of anti-tubercular therapy for two months. Paradoxically, the lesions continued to progress with pus discharges. A routine culture revealed no bacterial and fungal growth associated with the infection. On clinical examinations, few red erythematous papules with erosions and crusting seen over the site of prior the scar (Fig. 1b); no other systemic abnormality were found to be associated. Hence, the differential diagnosis of actinomycosis, deep mycosis, and rifampicin resistant cutaneous tuberculosis was made.

\section{Investigation}

On histopathological examination, multiple basophilic colonies surrounded by neutrophilic abscesses and granulation tissue with dense infiltration by acute and chronic inflammatory cells were observed. However, the serological marker: HIV, HBsAg, HCV (ELISA) were negative. The Renal function and Liver function were found normal. The level of tacrolimus was assessed $9.0 \mathrm{mcg} / \mathrm{dl}$.

As of microbiological approaches, for the detection of an etiologies: right angaled branching, filamentous Acid Fast Bacilli (AFB) was observed on Ziehl-neelson staining (Fig. 2); chalky white adherent colonies were seen on aerobic culture after $72 \mathrm{~h}$ of incubation, which turns molar tooth appearance on further incubation (Figs. 3 and 4). Further, identification of the isolate, Nocardia asteroids, was done with standard microbiological culture methods

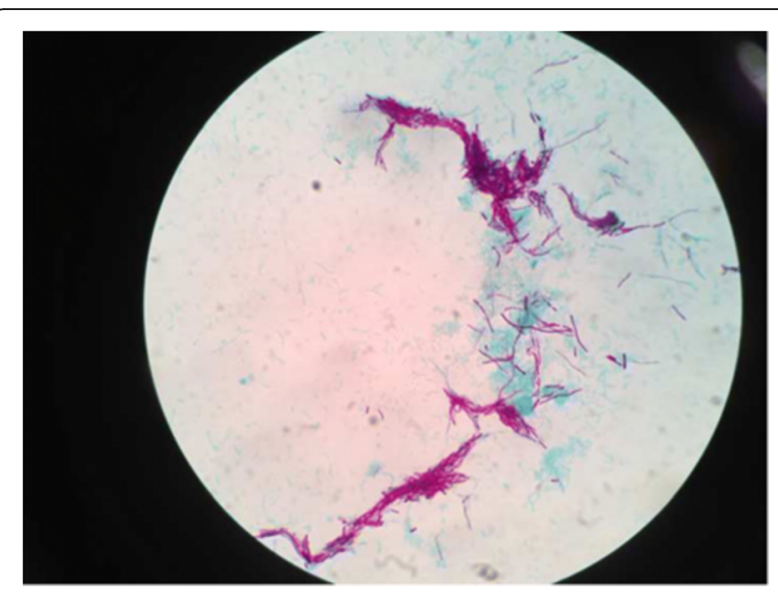

Fig. 2 AFB staining: partially acid-fast branching rod suggestive Nocardia species on modified. Kinyounstain (1000x original magnification)

as recommended by American Society for Microbiology, based on phenotypic characteristics, biochemical interpretations, and varied incubation temperature to grow the pathogen; since molecular analysis and sequencing was not accessible in our laboratory setting. Plus, antibiogram of the isolate was determined by modified Kirby-Bauer disk diffusion method on Blood agar against commercially prepared antibiotic disks (HiMedia Laboratories Pvt. Limited, India) in acquiescence with Clinical Laboratory Standards Institute (CLSI). Additionally, the CT scan of lungs and brain was done to rule out the possible disseminated nocardiosis; however, no abnormalities detected. In view of examination and investigations, a diagnosis of primary cutaneous nocardiosis was made on post-renal transplant patient. Subsequently, anti-tubercular therapy was discontinued, and the patient was treated with trimethoprime and sulfamethoxazole as per the drug susceptibility testing.

\section{Treatment}

The patient was treated with trimethoprime and sulfamethoxazole, BACTRIM-DS $(\mathrm{PO} \times \mathrm{BD}), 2$ double
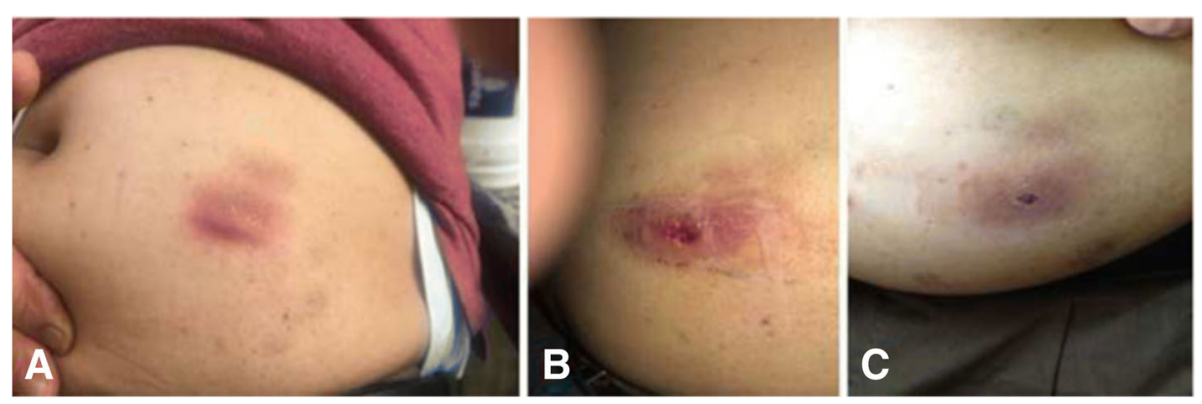

Fig. 1 a Red erythematous papules $\left(4^{*} 3 \mathrm{~cm}\right)$ of cutaneous nocardiosis. $\mathbf{b}$ Erythematous papules forming the plaque with erosions, pus discharge, and crusting. c The erythematous plaque reduced and resolve after successful treatment with TMP-SMX 


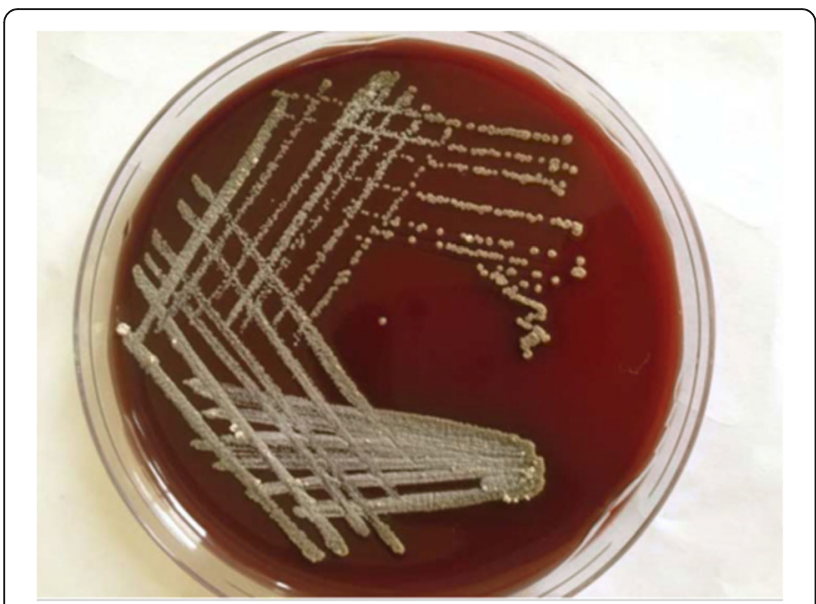

Fig. 3 Colonial morphology of Nocardia species on blood agar: whitish chalky adherent colonies of Nocardia species

strength oral tablets each containing $800 \mathrm{mg}$ sulfamethoxazole and $160 \mathrm{mg}$ trimethoprim for 3 months.

\section{Outcomes and follow-up}

He has now completed 2 months of treatment; has undergone progressive changes no relapse noted (Fig. 1c); transplant function observed in a good state. He is under regular follow up since then and we found him asymptomatic; however, with limited side effects due to prolonged antimicrobial therapy.

\section{Discussion}

Cutaneous nocardiosis is a rare infectious disease, presents as primary cutaneous infection or as a part of disseminated pulmonary nocardiosis [2]. The acquisitions of disseminated infection occur via inhalation of the pathogens which in-turn possibly metastasizes haematogenously to distant organs system (lungs, central

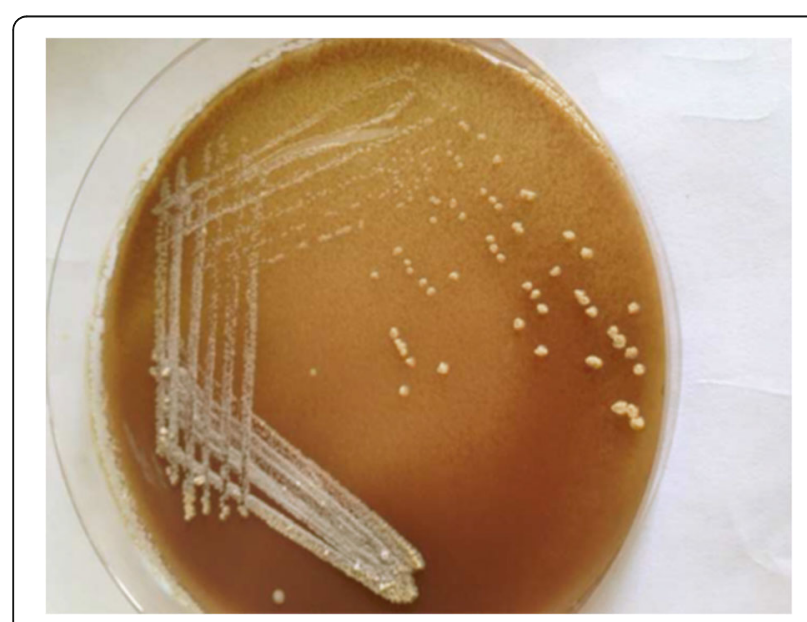

Fig. 4 Colonial morphology of Nocardia species on chocolate agar: whitish chalky adherent colonies of Nocardia species nervous system, eyes, kidneys, skin, subcutaneous tissue, and bone); nevertheless, inoculation of the pathogen after trauma, surgery, through a vascular catheter or by stings or scratches of animals may develop primary cutaneous nocardiosis [2, 4, 8-10].

Nocardiosis has been observed as an emerging infectious disease, probably due to increasing trend of treating the patient with immunosuppressive therapy and underlying diseases like HIV infection, diabetes, autoimmune disease, COPD, organ transplantation, lymphoreticular neoplasms [7, 10]. The high calcineurin inhibitor trough levels in months before diagnosis, use of tacrolimus and corticosteroid dose at the time of diagnosis, patient age, length of stay in intensive care unit after the solid organ transplant are independently associated with the development of nocardiosis $[6,10]$. Relating to our case; post-renal transplantation, lived with diabetes and hypertension, use of tacrolimus and corticosteroid dose at the time of diagnosis, patient age, and length of stay in intensive care unit after solid organ transplant could be the risk factor to acquire the infection.

The clinico-pathological manifestations of cutaneous nocardiosis are diverse. The precise diagnosis is often a challenge, due to its similar clinical presentations with other cutaneous diseases of different etiology and the relative difficulty in isolation of the pathogens in lesions [2]. In present case, the infections masqueraded as cutaneous tuberculosis preceding characteristic erythematous papules which eventually coalesced into plaques. Nevertheless, the clinical form masquerading: atypical zygomycosis, superficial celluitis or localized abscesses, lymphoadenities or lymphocutaneous infection, and even generalized limbs swelling; has also been reported in renal transplant recipient with presumed cutaneous nocardiosis [11-13]. The culture revealed no other bacterial and fungal growth in routine culture procedures (incubated for 24-48 h); however, the patient was treated empirically with anti-tubercular therapy for months, based on clinical presentations. The presumptive diagnosis could have made earlier with Ziehl-neelson staining and then with precise culture procedures implicated to Nocardia species, nevertheless. Therefore, when a persistent no growth on a clinical sample and impassive anti-tubercular regimen attributed; a differential diagnosis of cutaneous nocardiosis should be made.

The identification of Nocardia species in the clinical laboratory is challenging: may appear gram-negative and acid-fast-stain negative, require longer incubations period for growth [14]. In these perspectives, the clinicians must resort to every possible test, so that supporting positive rudiments would be an ancillary in the early and precise diagnosis of cutaneous nocardiosis. The presumptive identification of our case was done by AFB 
staining, bacterial culture with an extended incubation period, biochemical interpretations, and susceptibility pattern of the isolates to antibiotics; sequencing of 16SrRNA was not available in our setting, however.

Patient with primary cutaneous nocardiosis responds well to medical therapy. However, early detection of the pathogen, apt selection of the antimicrobial therapy, correct dosing and treatment duration is crucial in a successful management and treatment in cutaneous nocardiosis; limiting the tendency of late relapse $[15,16]$. Trimethoprim-sulfamethoxazole was chosen as a suitable antimicrobial therapy in our case, because of its good bioavailability in all tissue including the worst irrigated to bones, plus of its greater efficiency against most of the Nocardia species $[4,10]$. In addition, the patient receiving TMP-SMX confer lower relapse rate of about 13.6\% (compared to $32 \%$ mortality rate and $16 \%$ relapse rate in patients who did not receive TMP-SMX) $[3,17,18]$. The supplementary or alternate parenteral antimicrobial therapies-carbapenems (imipenem or meropenem, but not ertapenem), third-generation cephalosporins (cefotaxime or ceftriaxone), and amikacin, alone or in combinationalthough, recommended by some authors were thought unnecessary, because of possible toxicity relating to these drugs: cephalosporins and aminoglycosides-alone or in combinations-(nephrotoxic), carbapenem (myelosupression, optic nerve damage and lactic acidosis), linezolid (hematologic toxicity, lactic acidosis, optic neuritis or peripheral neuropathy) [3, 4, 18-22]. Scrutinizing these prospective, TMP-SMX has been considered, the appropriate treatment of choice. The clinical response to therapy of BACTRIM-DS $(\mathrm{PO} \times \mathrm{BD}), 2$ double strength tablets each containing $800 \mathrm{mg}$ sulfamethoxazole and $160 \mathrm{mg}$ trimethoprim was found evident within five days of medication in our case, even though the medications were continued for 3 months.

Moreover, the relative rarity of the cases, non-specific clinico-pathological presentations, diagnostic intricacies, and with lack of systematic reporting; the exact burden of nocardiosis in low-income countries like Nepal is not clear but speculated to be small.

\section{Conclusion}

The challenges in establishing the precise diagnosis of cutaneous nocardiosis often encountered, in clinical practice, due to the relative paucity of the pathogen in lesions, multifaceted clinico-pathological features as of cutaneous diseases with different etiology, and inherent difficulty in-vitro cultivating. Henceforth, particularly in the renal transplant recipient, a high degree of clinical suspicions, early detection of the pathogen, apt selection of the antimicrobial therapy, correct dosing and treatment duration is crucial for successful outcomes.

\section{Abbreviation}

AFB: Acid Fast Bacilli; ATT: Anti-Tubercular Treatment; CLSI: Clinical and Laboratory Standard Institute; COPD: Chronic Obstructive Pulmonary Disease; CT: Computerized Tomography; HBsAg: Hepatitis B surface antigen; HCV: Hepatitis C Virus; HIV: Human Immune deficiency Virus; LFTs: Liver Function test; RFT: Renal Function test; TMP-SMX: Trimethoprim-

sulfamethoxazole

\section{Acknowledgments}

We would like to thank Mr. Pradeep Sharma (Civil Service Hospital) his tremendous technical support.

\section{Availability of data and materials}

All data generated or analyzed during this study are included in this published article.

\section{Authors' contributions}

PK conceived the study, design the manuscript, review of the literature. DS reviewed the manuscript and give the concept of the research paper and critically reviewed the manuscript. Both authors read and approved the manuscript

Ethics approval and consent to participate

There is no need for ethical approval for a case report according to the local ethical guidelines. Written informed consent was obtained from the patient for granting participation in an interview and to extract pertinent sociodemographic and clinical data from their respective clinical files, respecting confidentiality.

\section{Consent for publication}

Written informed consent was obtained from the patient for publication of this case report and any accompanying images.

\section{Competing interests}

The authors declare that they have no competing interests.

\section{Publisher's Note}

Springer Nature remains neutral with regard to jurisdictional claims in published maps and institutional affiliations.

\section{Author details}

'Department of Microbiology, Tribhuvan University Teaching Hospital, Kathmandu, Nepal. ${ }^{2}$ Medical Microbiology, Tri-Chandra Multiple Campus, Tribhuvan University, Ghantaghar, Kathmandu, Nepal. ${ }^{3}$ Department of Nephrology and Renal Transplantation Medicine, Grande International Hospital, Kathmandu, Nepal.

Received: 18 April 2018 Accepted: 20 September 2018

Published online: 01 October 2018

\section{References}

1. Villafafie F. Nocardiosis: a review. Int J Infect Dis. 2003;7(4):243-50 Available from: https://www.ncbi.nlm.nih.gov/pubmed/14656414.

2. Atzori L, Pinna AL, Pau M. Cutaneous Nocardiosis. SOJ Microbiol Infect Dis, 2014;(1):1-8.

3. Wilson JW. Nocardiosis : updates and clinical overview. JMCP 2012;87(4): 403-407. Available from: https://doi.org/10.1016/j.mayocp.2011.11.016

4. Malet A, De Gañan I. Nocardiosis in solid organ transplant. J Immunol Clin Res. 2017;4(2):1-5.

5. Nocardiosis SOF, Of R, Cases T. Spectrum of Nocardiosis - a report of three cases. J Clin Diagnostic Res. 2009;4:1682-4.

6. Vigil KJ, Pasumarthy A, Johnson LB, Sheppard T, El-Ghoroury M, Del Busto R. Nocardiosis in renal transplant patients: role of current immunosuppressant agents. Infect Dis Clin Pract. 2007;15(3):171-3.

7. Alavi Darazam I, Shamaei M, Mobarhan M, Ghasemi S, Tabarsi P, Motavasseli $\mathrm{M}$, et al. Nocardiosis: risk factors, clinical characteristics and outcome. Iran Red Crescent Med J [Internet]. 2013;15(5):436-439. Available from: https:// www.ncbi.nlm.nih.gov/pmc/articles/PMC3838657/.

8. Sagar R, Challa S. Pathology and diagnosis of Nocardiosis. J Sci Med Cent. 2017;2(5):2-1042. 
9. Saubolle MA, Sussland D. Nocardiosis : Review of Clinical and Laboratory Experience. J Clin Microbiol. 2003:41(10):4497-501.

10. Coussement J, Lebeaux D, Van Delden C, Guillot H, Freund R, Marbus S, et al. Nocardia infection in solid organ transplant recipients: a multicenter European case-control study. Clin Infect Dis. 2016;63(3):338-45.

11. Kim YK, Oh JR, Choi HK, Kim HY, Park SD, Uh Y. Primary cutaneous nocardiosis caused by Nocardia nova in a kidney transplant recipient. J Med Microbiol. 2013;63(PART 1):140-3.

12. Lyngdoh W, Mawlong M, Sailo S, Khyriem A. Sub-cutaneous abscess caused by Nocardia asteroides in renal transplant recipient. Indian J Med Sci. 2011; 65(4):172 Available from: https://www.ncbi.nlm.nih.gov/pubmed/23250348.

13. Colón-Santos E, González-Ramos M, Bertrán-Pasarell J, Rodríguez-Vega G, Almira-Suarez M, Vélez-Rosario R. Disseminated nocardiosis masking an atypical zygomycosis presentation in a kidney transplant recipient. Transpl Infect Dis. 2011;13(4):380-4.

14. Brown-Elliott BA, Brown JM, Conville PS, Wallace RJ. Clinical and laboratory features of the Nocardia spp. Based on current molecular taxonomy clinical and laboratory features of the Nocardia spp. based on current molecular taxonomy. Clin Microbiol Rev. 2006;19(2):259-82.

15. Inamadar AC, Palit A. Study primary cutaneous nocardiosis: a case study and review. Indian J Dermatol Venereol Leprol. 2003;69(6):386-91.

16. Ojha N, Bista KDB, Torres OH, Domingo P, Pericas R, Boiron P, et al. Clinical and radiographic characteristics of pulmonary Nocardiosis: clues to earlier diagnosis. PLoS One. 2014:57(3):807-12.

17. Tiemessen $C T$, Shalekoff $S$. Antituberculosis treatment: increasing evidence for drug effects on innate cellular immunity. Clin Diagn Lab Immunol. 2001; 8(4):686-9.

18. Welsh O, Vera-Cabrera L, Salinas-Carmona MC. Current treatment for nocardia infections. Expert Opin Pharmacother [Internet]. 2013;14(17):238798 Available from: https://www.ncbi.nlm.nih.gov/pubmed/24093436.

19. Clark NM, Reid GE. Nocardia infections in solid organ transplantation. Am J Transplant. 2013;13(SUPPL.4):83-92.

20. Khadka P, Basnet RB, Khadka P, Shah DS, Pokhrel BM. Disseminated Nocardiosis in renal transplant recipient under therapy for pulmonary tuberculosis: a case report. BMC Res Notes. 2017:1-7.

21. Khadka P, Mishra SK, Shah DS, Rijal BP. Case report: primary pulmonary Nocardiosis and Candidosis with cutaneous involvement in nephrotic syndrome patient under steroid therapy. Int J Clin Case Reports. 2016; 6(11):1-7.

22. Yaich S, Charfeddine K, Zaghdane S, EA N, Masmoudi M, et al. Pulmonary Nocardiosis in a kidney transplant recipient : a case report and review of the literature. J Transpl Technol Res. 2011;(1, 2):2-4.

Ready to submit your research? Choose BMC and benefit from:

- fast, convenient online submission

- thorough peer review by experienced researchers in your field

- rapid publication on acceptance

- support for research data, including large and complex data types

- gold Open Access which fosters wider collaboration and increased citations

- maximum visibility for your research: over $100 \mathrm{M}$ website views per year

At $\mathrm{BMC}$, research is always in progress.

Learn more biomedcentral.com/submissions 